\title{
Impact of Health Talks on Knowledge, Attitudes and Perception of Breast Cancer Screening and Treatment Amongst Healthcare Staff by a Breast Surgical Unit in a Public Healthcare Institution - A Cross Sectional Study
}

Jeffrey Jun Xian Hing ( $\nabla$ hing.jun.xian@singhealth.com.sg )

Changi General Hospital https://orcid.org/0000-0003-4215-4932

Wai Peng Lee

Changi General Hospital

Yen Nee Sophia Chua

Changi General Hospital

Pei Ting Tan

Changi General Hospital

Chi Wei Mok

Changi General Hospital

Spoorthi Shetty Sudhakar

Changi General Hospital

Chin Mui Seah

Changi General Hospital

Su-Ming Tan

Changi General Hospital

\section{Research article}

Keywords: Changi General Hospital (CGH), cancer screening, Breast Cancer

Posted Date: January 15th, 2021

DOI: https://doi.org/10.21203/rs.3.rs-144236/v1

License: (1) (i) This work is licensed under a Creative Commons Attribution 4.0 International License.

Read Full License 
Version of Record: A version of this preprint was published at BMC Women's Health on August 21st, 2021. See the published version at https://doi.org/10.1186/s12905-021-01424-z. 


\section{Abstract}

Background: In October 2019, surgeons from Changi General Hospital (CGH) Breast Centre delivered a series of health talk for its employees to assess the knowledge and perception of breast cancer screening and improve related knowledge of the institution's healthcare workers. This is to enable CGH, a healthcare provider to not only care for our patients, but also look after its staff.

Methods: 141 hospital staff attended a 40-minute talk followed by an open question and answer forum. Pre and post talk surveys were conducted to gauge knowledge, attitudes, beliefs and misconceptions towards breast cancer screening and treatment. Question domains were divided into 1) breast cancer knowledge, 2) breast cancer screening guidelines,3) attitudes and perception of breast cancer screening and treatment. Univariate and multivariate logistic regression analysis was used to examine the relationship between demographics and performance in question domains.

Results: The overall response rate was 131 out of a total of 141 attendees (92.9\%). The median age was 44 (range, 22 to 67 ), with nursing staff making up $40 \%$ of the cohort. Analysis showed statistically significant improvement in median score across all 3 domains. $(p<0.05)$ after the forum. We found that respondents who were women $\geq 40$ years (eligible age for screening), had higher income, lived in larger housing types, had attended previous talks, had served $>10$ years in healthcare and had personal encounter with breast cancer patients performed better. Surprisingly, being a nurse or having a university degree did not translate to better score. $99 \%$ of respondents find the forum beneficial and will recommend to others.

Several knowledge gap about breast cancer screening and misconceptions were identified. Future campaign should focus on raising awareness of the national screening program BreastScreen Singapore. We advocate to reinforce its recommendations, promote on the affordability and ready accessibility. As healthcare personnel are ambassadors of the healthcare system, their knowledge would aid in providing accurate information to patients and public, enabling them to make wise healthcare choices.

Conclusions: A simple Breast Cancer Awareness Month campaign targeted at healthcare workers was found to be effective at educating hospital staff on breast cancer, screening practices and improving perception of screening and treatment practices. This may empower them to not only care for themselves but help serve patients better.

\section{Background}

Breast cancer is the most common and lethal cancer amongst women in Singapore, accounting for $17.3 \%$ or 2,105 deaths from all cancer in women in Singapore from 2011 to 2015 [1]. Moreover, the age standardised incidence rate of breast cancer has jumped more than 2.5 times over the last four decades from 24.6 to 65.3 per 100,000 population per year [1]. After the Singapore Breast Screening Project in 1994 and the national breast cancer screening programme, BreastScreen Singapore (BSS), was launched in 2002. Despite, considerable efforts made to encourage women to go for screening, uptake rates remain 
low $[2,3]$. Regular campaign activities such as talks conducted during the Breast Cancer Awareness Month (BCAM) in October are targeted to promote awareness, so as to increase screening uptake.

Healthcare workers are a direct source of medical information to the public and patients. Due to their frequent contact with patients and public, they are often looked upon to provide accurate health related information. It is therefore essential, that they convey facts that are accurate, thereby promoting health awareness amongst the population.

In October 2019, breast surgeons from the Breast Centre, Changi General Hospital (CGH), a public healthcare institution in the Eastern part of Singapore, delivered a series of talks on breast cancer and mammographic screening to its employees. We took the opportunity to assess the participants' knowledge, perception and practice with regards to breast cancer screening before and after the talk. The aim of this study is to determine the effectiveness of the breast cancer awareness talks at identifying areas of knowledge gap amongst healthcare workers, clarifying common misconceptions on breast screening and improving perception towards breast cancer treatment.

\section{Methods}

In October 2019, three health talks were conducted by CGH breast surgeons for staff members. Invitation was extended to all staff via email, intranet announcement and posters within the hospital premise. The content covered included epidemiology, signs and symptoms, risk factors of breast cancer, breast cancer screening guidelines, costs and accessibility to screening services. Common myths and misconceptions regarding breast cancer, screening and treatment were also addressed. All three talks had the same content but were conducted on different days in order to allow more staff to attend.

A self-administered questionnaire in English was conducted before and after the talk (Appendix 1). This questionnaire was adapted from a previous study looking at knowledge and perception of breast screening in Singapore [4]. A validity test was not performed on the questionnaire. The questionnaire was designed to assess three domains - knowledge of breast cancer, knowledge of breast cancer screening in Singapore and attitudes and perception towards breast cancer screening and treatment. The questions and answers are in Appendix 1 and 2. The list of accepted answers was not exhaustive and answers with similar implied meaning were accepted. Feedback with regards to the talk (duration, usefulness and content) was also obtained.

Participation of the questionnaires was strictly voluntary and anonymous. An immediate response was requested, and the questionnaires were collected upon completion. Participants were encouraged not to discuss the answers with each other. Entries were checked by study assistants to ensure completeness of response to maintain a high fidelity and response rate. Ethics board review was deemed not necessary by the Singhealth Centralised Institutional Review Board (CIRB Ref no. 2019/ 2829)

The data including, total correct responses percentages before and after the health talk, was analysed with Chi-square test. We calculated pre and post questionnaire median scores and chose a 75th 
percentile as cut off score to analyse the group of better performing respondents according to their demographic characteristics. We determined the correlation of variables to predict for better scores. Multivariate analysis was performed on the statistically significant variables, using logistic regression analysis, with the Statistical Package for the Social Sciences (SPSS) version 18.0 (SPSS Inc, Chicago, IL, USA). A $P$ value of $<0.05$ was taken to be statistically significant.

\section{Results}

\section{Demographics}

The overall response rate was $92.9 \%$ (131 out of a total of 141 attendees). The median age of the respondents was 44 years (range: 22 to 67 ). Chinese participants formed $50.4 \%$ of our respondents. The majority $(97.9 \%)$ of respondents were female, nurses $(40.4 \%)$ and were diploma/degree holders $(85.1 \%)$ (Table 1). 
Table 1

Respondents' demographics, working experience and exposure to family, friends and/or patients with breast cancer $(n=141)$

\begin{tabular}{|ll|}
\hline Demographics & Respondents (\%) \\
\hline Age * & \\
\hline 40 & $88(62.4)$ \\
$\geq 50$ & $27(19.1)$ \\
\hline Ethnic group & $26(18.4)$ \\
Chinese & \\
Malay & $71(50.4)$ \\
Indian & $35(24.8)$ \\
Eurasian & $9(6.4)$ \\
Others & $2(1.4)$ \\
Gender & $24(17.0)$ \\
Male & \\
Female & $3(2.1)$ \\
Highest Education Completed & $138(97.9)$ \\
Primary or below & \\
Secondary & $0(0.0)$ \\
Diploma (Polytechnic, A level, ITE) & $13(9.2)$ \\
University Degree holder & $28(19.9)$ \\
Missing & $92(65.2)$ \\
\hline
\end{tabular}

*age group categorised according to BreastScreen Singapore guidelines [5]

$<40$ : not recommended for screening mammograms

40-49: to consider annual mammograms

$\geq 50$ : recommended for biennual screening mammograms 


\begin{tabular}{|ll|}
\hline Demographics & Respondents (\%) \\
\hline Healthcare profession & $0(0.0)$ \\
Doctor & $57(40.4)$ \\
Allied Health & $36(25.5)$ \\
Administrative staff/ Others & $48(34)$ \\
\hline Gross personal monthly income (SGD) & \\
\hline \$2000 & $9(6.4)$ \\
\$2000 - \$3999 & $64(45.4)$ \\
\$4000 - \$5999 & $49(34.8)$ \\
\$6000 and above & $13(9.2)$ \\
\hline Housing & \\
\hline Rental/1-2 room apartment & $11(7.8)$ \\
3 room apartment & $16(11.3)$ \\
$4-5$ room/executive apartment & $92(65.2)$ \\
Executive Condominium & $11(7 / 8$ \\
Landed property & $2(1.4)$ \\
Missing & $9(6.4)$ \\
\hline Family history of breast cancer & \\
Yes & $16(11.3)$ \\
No & $113(80.1)$ \\
\hline Missing & $4(2.8)$ \\
\hline
\end{tabular}

*age group categorised according to BreastScreen Singapore guidelines [5]

$<40$ : not recommended for screening mammograms

40-49: to consider annual mammograms

$\geq 50$ : recommended for biennual screening mammograms 


\begin{tabular}{|c|c|}
\hline Demographics & Respondents (\%) \\
\hline Know of relative who have breast cancer & $52(36.9)$ \\
\hline Yes & $70(49.6)$ \\
\hline No & $11(7.8)$ \\
\hline Don't know & $8(5.7)$ \\
\hline \multicolumn{2}{|l|}{ Missing } \\
\hline Know of friends who have breast cancer & $63(44.7)$ \\
\hline Yes & $64(45.4)$ \\
\hline No & $6(4.3)$ \\
\hline Don't know & $8(5.7)$ \\
\hline \multicolumn{2}{|l|}{ Missing } \\
\hline Had previously \&/or currently been involved in the care of breast cancer patients & $42(29.8)$ \\
\hline Yes & $90(63.8)$ \\
\hline No & $9(6.4)$ \\
\hline \multicolumn{2}{|l|}{ Missing } \\
\hline Attended previous similar health talk & $97(68.8)$ \\
\hline No & $43(30.5)$ \\
\hline Yes & $1(0.7)$ \\
\hline \multicolumn{2}{|l|}{ Missing } \\
\hline Duration in Healthcare & $75(53.2)$ \\
\hline$\leq 10$ years & $64(45.4)$ \\
\hline$>10$ years & $2(1.4)$ \\
\hline \multicolumn{2}{|l|}{ Missing } \\
\hline \multicolumn{2}{|l|}{ *age group categorised according to BreastScreen Singapore guidelines [5] } \\
\hline \multicolumn{2}{|l|}{$<40$ : not recommended for screening mammograms } \\
\hline \multicolumn{2}{|l|}{ 40-49: to consider annual mammograms } \\
\hline$\geq 50$ : recommended for biennual screening mammograms & \\
\hline
\end{tabular}


Slightly more than half (53.2\%) have been working in healthcare for 10 years or less with two-thirds $(68.8 \%)$ not having attended similar talks. Most did not have a family history of breast cancer $(80.1 \%)$ and had not been involved in the care of breast cancer patients (63.8\%) (Table 1).

\section{Domain 1 - Knowledge of breast cancer}

The improvement in knowledge scores pre and post-talk was statistically significant in 16 out of 27 questions as detailed in Table $2(P<0.05)$. The main areas of pre-talk knowledge deficit (which was defined as having less than $50 \%$ of the cohort having the correct responses) were: signs and symptoms of breast cancer, risk factors, and the stages of breast cancer. These are indicated with asterisks in table 2.

After the talk, there was significant improvement in scores of more than $50 \%$ absolute increase in correct respondents in 3 questions, namely risk factors of breast cancer, stages of breast cancer, and the costs of screening mammograms for Singaporeans. $41.2 \%$ more respondents were aware of BSS and $42.0 \%$ more respondents knew the correct interval of screening mammograms after the talk.

However, post-talk, $24.4 \%$ of the respondents still believed that traditional medicine is part of treatment for breast cancer.

Table 2. Number (\%) of respondents achieving the correct answer pre and post talk $(n=131)$

*weaker areas defined as less than $50 \%$ of cohort scored correctly 


$\begin{array}{llll}\begin{array}{l}\text { Pre- } \\ (\%)\end{array} & \text { Post (\%) } & \begin{array}{l}\% \\ \text { increase }\end{array} & \begin{array}{l}\text { value } \\ \end{array}\end{array}$

Knowledge of breast cancer

1. What is the most common cancer in Singapore women

2. Is breast cancer a common cancer among

Singapore women

3. Name two risk factors for breast cancer*

4. Name two symptoms of breast cancer* 105 (80.2)

124 (94.7) 28 (21.4) 59 $(45.0)$

5. Stage 0 *

6. Stage1

7. Stage 2

8. Stage 3

9. Stage 4

Treatment of breast cancer may involve

10. Traditional medicine

11. Surgery

12. Chemotherapy

13. Radiotherapy

10. Traditional medicine

(a)

and

\section{4}

(33.6)

123

(93.9)

127

(96.9)

123

(93.9)

117
$(89.3)$
$122(93.1)$

59.5

0.001

$82(62.6) \quad 17.6 \quad 0.001$
$<0.001$ 0.031 $51.9<0.001$
Breast cancer has different stages as follows 
going for breast screening

(70.2)

4. Correctly identify the interval for breast screening * 47

5. Correctly name 2 places that screening mammograms are available (specific) *

6. Correctly identify how much a screening mammogram costs at the BSS screening centre for Singaporeans? *

$102(77.9)$

42.0 $<0.001$

7. Can Medisave ${ }^{+}$be used to pay for screening mammogram for women $\geq 50$ years old?

$69(52.7)$

38.2 $<0.001$

8. How often women should do breast selfexamination (BSE)?

Attitudes and perceptions of Breast cancer screening and treatment

1. Women should only go for a mammogram when they have a breast problem eg lump

2. I think that regular screening mammogram will not affect the shape of the breasts

3. If there is an abnormality in the breast, the $1^{\text {st }}$ thing I would do or advise others to do is to see a doctor

4. Will there be a higher chance of cure if breast cancer is detected early?

5. Surgery for breast cancer always needs the whole breast to be removed

6. Surgery for breast cancer will cause the affected arm to swell and be crippled
77

(58.8)

112

(85.5)

114

(87.0)

$87(66.4)$

7.6

0.174

$115(87.8)$

22.9

$<0.001$

$116(88.5) \quad 3.0$

0.535

127 (96.9)

9.9

0.004

(92.4)

121

130 (99.2)

6.8

0.004

127

(96.9)

$130(99.2)$

2.3

0.375

105

(80.2)

$115(87.8)$

7.6

0.052

86

(65.6)

$111(84.7)$

19.1

$<0.001$

+MediSave is a compulsory national saving scheme in Singapore

\section{Domain 2 - Knowledge of breast cancer screening}

Generally, there was poor knowledge of breast screening amongst the respondents. Prior to the talk, almost half (44.3\%) have not heard of BSS. Most (62.6\%) were unaware that screening mammogram was to be done when there are no breast symptoms or problems and $85.5 \%$ were unable to correctly name two locations for screening mammograms. Almost two-thirds (64.1\%) did not know the recommended interval for routine screening mammograms. Majority $(72.8 \%)$ did not know the costs of a screening mammogram, with more than $50 \%(n=74)$ believed that it cost more than SGD $\$ 100$, when in fact, it costs SGD $\$ 50$ when done at the BSS screening centres. 
After the talk, the respondents displayed a significant improvement $(p<0.05)$ in most areas. Although there was improvement in their understanding of what is considered to be screening mammogram (37.4 to $45.0 \%$ ) and the knowledge that Medisave (a national compulsory saving scheme) can be used to pay for the screening mammograms (58.8 to $66.4 \%$ ), it did not reach statistical significance. [6]

Despite a significant improvement, $47.3 \%$ of the respondents were still unable to accurately name two locations to perform screening mammogram and $22.1 \%$ were unaware of the correct interval for screening mammogram.

\section{Domain 3 - Attitudes and perception of breast cancer screening and treatment}

Most of the respondents ( $>80 \%$ ) provided correct answers to the questions in this domain, except for the question on the effect of breast cancer surgery on the ipsilateral arm. Fortunately, there was significant improvement after the talk, from $65.6-84.7 \%(p<0.05)$.

In terms of personal practice, only $31.5 \%(34 / 108)$ of eligible respondents had gone for screening mammogram. After the talk, $82 \%$ of the respondents reported that they would go for screening mammogram and most (99\%) would recommend their family and friends to go for screening too.

\section{Scores}

The total score for all three domains was 27. The mean total score pre-talk was 19 (range: 9 to 26). There was a significant improvement of the post-talk mean score to 24 (range: 15 to 27$)(p<0.05)($ Fig. 1$)$. Using the 75th percentile as cut-off, a high score on knowledge was arbitrarily defined as those with a score of $>21(22 / 27=81.5 \%)$ and a low score was defined as those with a score of $\leq 21$. There was a significant improvement in the percentage of overall good performers and a consistent improvement in mean scores across all 3 domains (Table 3 ). Of the three domains, respondents fared worst in the knowledge of breast cancer screening. 
Table 3

Proportion (\%) of poor and good performers, breakdown of mean scores in all 3 domains pre and posttalk.

\begin{tabular}{|c|c|c|c|c|c|}
\hline & & \multicolumn{2}{|l|}{ Pre-talk (\%) } & \multicolumn{2}{|l|}{ Post-talk (\%) } \\
\hline \multicolumn{2}{|l|}{$\begin{array}{l}\text { Poor performers (scoring } \leq \\
21 / 27 \text { ) }\end{array}$} & \multicolumn{2}{|l|}{$\mathrm{n}=96(73.3)$} & \multicolumn{2}{|l|}{$\mathrm{n}=22(16.8)$} \\
\hline \multicolumn{2}{|l|}{$\begin{array}{l}\text { Good performers (scoring > } \\
21 / 27 \text { ) }\end{array}$} & \multicolumn{2}{|l|}{$\mathrm{n}=35(26.8)$} & \multicolumn{2}{|l|}{$n=109(83.2)$} \\
\hline \multicolumn{2}{|l|}{ Average scores } & \multicolumn{2}{|c|}{19 (range: 9 to 26 ) } & \multicolumn{2}{|c|}{24 (range:15 to 27 ) } \\
\hline Domains & $\begin{array}{l}\text { Total } \\
\text { score }\end{array}$ & $\begin{array}{l}\text { Average } \\
\text { score among } \\
\text { poor } \\
\text { performers } \\
(\%)\end{array}$ & $\begin{array}{l}\text { Average } \\
\text { score among } \\
\text { good } \\
\text { performers } \\
(\%)\end{array}$ & $\begin{array}{l}\text { Average } \\
\text { score among } \\
\text { poor } \\
\text { performers } \\
(\%)\end{array}$ & $\begin{array}{l}\text { Average } \\
\text { score among } \\
\text { good } \\
\text { performers } \\
(\%)\end{array}$ \\
\hline $\begin{array}{l}\text { 1. Knowledge of breast } \\
\text { cancer }\end{array}$ & 13 & $9.54(73.4)$ & $11.34(87.2)$ & $10.27(79.0)$ & $12.12(93.2)$ \\
\hline $\begin{array}{l}\text { 2. Knowledge of breast } \\
\text { cancer screening }\end{array}$ & 8 & $3.72(46.5)$ & $6.09(76.1)$ & $4.41(73.5)$ & $7.04(88.0)$ \\
\hline $\begin{array}{l}\text { 3. Attitudes and } \\
\text { perceptions of Breast } \\
\text { cancer screening and } \\
\text { treatment }\end{array}$ & 6 & $4.01(66.8)$ & $4.80(80.0)$ & $5.07(84.5)$ & $5.56(92.7)$ \\
\hline
\end{tabular}

The scores were analysed against the demographic, working experience and exposure to family, friends and/or patients with breast cancer of the respondents. We found that respondents who were women $\geq$ 40 years (eligible age for screening), had higher income, lived in larger housing types, had attended previous talks, had served $>10$ years in healthcare and had personal encounter with breast cancer patients performed better. Surprisingly, being a nurse or having a university degree did not translate to better score (Table 4). Having a non-nursing background and longer duration of service were the two statistically significant variables that predicted for better scores in the pre-talk analysis. 
Table 4

Multivariate logistics regression on pre-talk knowledge scores

Knowledge

Poor Good

(\%) (\%)
Univariate

OR $(95 \% \mathrm{Cl})$
Multivariate

$\mathrm{P} \quad \mathrm{OR}(95 \% \mathrm{Cl}) \quad \mathrm{P}$

value value

Age

$<40$

67

16

REF

REF

$>=40$

$29 \quad 19$

(60.4)

(39.6)

2.74 (1.24,

6.08)

0.013

$1.67(0.55$,

5.08)

0.364

Education

Non-University

25

(67.6)

12

(32.4)

REF

REF

University

$66 \quad 21$

(75.9)

21

(24.1)

$0.66(0.29$,

1.54)

0.341

$1.73(0.51$,

5.91)

0.380

Occupation

Non-nurse

54

(56.8)

22

(62.9)

Nurse

41

(75.9)

13

13
$(24.1)$

$0.78(0.35$,

1.73)

REF

REF

Personal income

$<\$ 4000$

$$
30
$$

(83.3)

6
(16.7)

REF

REF

$>=4000$

$52 \quad 26$

(66.7) (33.3)

$2.50(0.92$

6.76)

0.071

$1.45(0.39$

$5.42)$

$0.18(0.05$,

$0.64)$

0.008

Housing type

3 room and smaller / rented

21

(84.0) (16.0)

4-5 rooms

EC / private

Know someone with breast

cancer

$64 \quad 23$

(73.6) (26.4)

$1.89(0.59$,

6.08)

65

(54.5)
$5 \quad 4.38(0.89$,

(45.5) 21.61)
REF

0.288

$0.74(0.16$,

3.29)

0.070

$3.18(0.36$,

28.21)
0.578

0.687

0.298

* Multivariate analysis included age, education level, occupation, personal income, housing type, family history, relative and/or friends with breast cancer, attended previous talk, duration of working in healthcare 


\begin{tabular}{|c|c|c|c|c|c|c|}
\hline \multirow[b]{2}{*}{ No } & \multicolumn{2}{|c|}{ Knowledge } & \multicolumn{2}{|l|}{ Univariate } & \multicolumn{2}{|l|}{ Multivariate } \\
\hline & $\begin{array}{l}26 \\
(28.6)\end{array}$ & $\begin{array}{l}5 \\
(15.2)\end{array}$ & REF & & REF & \\
\hline Yes & $\begin{array}{l}65 \\
(71.4)\end{array}$ & $\begin{array}{l}28 \\
(84.8)\end{array}$ & $\begin{array}{l}2.24(0.78 \\
6.43)\end{array}$ & 0.134 & $\begin{array}{l}1.81(0.50 \\
6.56)\end{array}$ & 0.368 \\
\hline \multicolumn{7}{|c|}{ Attended talk previously } \\
\hline No & $\begin{array}{l}69 \\
(77.5)\end{array}$ & $\begin{array}{l}20 \\
(22.5)\end{array}$ & REF & & REF & \\
\hline Yes & $\begin{array}{l}26 \\
(63.4)\end{array}$ & $\begin{array}{l}15 \\
(36.6)\end{array}$ & $\begin{array}{l}1.99(0.89 \\
4.46)\end{array}$ & 0.095 & $\begin{array}{l}1.65(0.56 \\
4.88)\end{array}$ & 0.366 \\
\hline \multicolumn{7}{|c|}{ Working in healthcare } \\
\hline$<=10$ years & $\begin{array}{l}59 \\
(85.5)\end{array}$ & $\begin{array}{l}10 \\
(14.5)\end{array}$ & REF & & REF & \\
\hline$>10$ years & $\begin{array}{l}35 \\
(58.3)\end{array}$ & $\begin{array}{l}25 \\
(41.7)\end{array}$ & $\begin{array}{l}4.21(1.81, \\
9.80)\end{array}$ & 0.001 & $\begin{array}{l}4.76(1.36 \\
16.62)\end{array}$ & 0.014 \\
\hline
\end{tabular}

We further analysed the nurses' performance in the 3 domains and found that the mean score for knowledge on breast cancer and attitude and perception about breast cancer screening and treatment were higher than average at 11.1/13 (85.3\%) and 5.2/6 (86.7\%) respectively, but lower than average for knowledge on breast cancer screening at 4.7/8 (58.7\%) (Table 3).

\section{Feedback}

In general, the talks were well received, with $99 \%$ of respondents finding the talk beneficial and will recommend to others to attend. $89.4 \%$ identified health talks as their preferred source of information on breast cancer (Table 5). 
Table 5

Respondents' preferred medium for future health awareness campaigns (\%)

\begin{tabular}{|ll|}
\hline Health talks/ public forums & $\mathbf{1 2 6}(\mathbf{8 9 . 4 )}$ \\
\hline TV & $96(68.1)$ \\
\hline Printed materials such as posters, brochures & $91(64.5)$ \\
\hline Internet & $77(54.6)$ \\
\hline Family doctors & $50(35.5)$ \\
\hline Email & $21(14.9)$ \\
\hline SMS & $15(10.6)$ \\
\hline Health App & $74(52.5)$ \\
\hline
\end{tabular}

\section{Discussion}

\section{Scores}

Our study showed statistically significant improvement of knowledge scores before and after the BCAM talks in all three domains of questions (Fig. 1, Tables 2 and 3). The weakest performing domain was the domain on breast cancer screening. Fortunately, the post-talk questionnaire showed the improvement in knowledge of breast screening to be the greatest. This may be due to the fact that healthcare staff who work in a tertiary hospital, that is not a screening centre, are therefore not be familiar with screening practices. Thus, this would be an area that future talks to healthcare staff should place more emphasis on.

The multivariate logistic regression revealed that working $>10$ years in healthcare and non-nurses had better performance, suggesting that having a nursing background did not translate to better overall scores. Our subgroup analysis revealed that although nurses performed worst in the knowledge of breast cancer screening, but they had above average scores in knowledge of breast cancer, attitudes and perceptions towards treatment. This was similar to previous studies that showed that nurses in a tertiary hospital lacked knowledge in screening even though they are aware of the symptoms, risk factors, treatment and natural history of the breast cancer $[7,8]$. Chong et al also reported that nurses in hospital setting fared worse than their counterparts in primary health in terms of breast screening knowledge [9]. Heena et al also reported that the knowledge attitudes and practices related to breast cancer screening among healthcare professionals were found to be lower than expected. [10]

The authors postulate that as CGH was not a screening centre, nurses were more accustomed to managing symptomatic breast conditions and hence lacked work experience in areas of breast cancer screening. Another possible explanation could be that the nurses who attended the talk were a bias 
group. As a large number of nurses work shift duties, they may not be able to attend the talks. Hence those who attended are a bias group who may not be representative of the entire nursing population in the hospital. However, the authors take comfort in that, despite their initial poorer knowledge, their scores improved significantly after the talk.

\section{Knowledge gap}

\section{Domain 1 - Knowledge on breast cancer}

Despite a significant improvement in knowledge of risk factors and symptoms of breast cancer post-talk, $26.7 \%$ and $37.4 \%$ of the respondents respectively were still unable to provide correct answers for these after the talk. This suggests that the talk was effective in improving knowledge, but perhaps in future talks, more emphasis could be place in these specific areas.

Post-talk, $24.4 \%$ still held the belief in treatment for breast cancer may involve traditional medicine. These are areas that might have to be emphasized in future talks. This may be due to the deep-rooted cultural beliefs in traditional remedies in the predominantly Asian population in Singapore. A local study found that although knowledge in complementary and alternative medicine (CAM) is severely lacking, almost half of the surveyed population continued to use CAM concurrently with conventional medicine and up to $70 \%$ would not consult a doctor or pharmacist when using CAM [11). Future talks should highlight the lack of scientific evidence on CAM in breast cancer treatment.

\section{Domain 2 - Knowledge on breast cancer screening}

This is the weakest performing domain before and after the talk. Despite significant post-talk improvement, $22.1 \%$ and $47.3 \%$ of the respondents were still unaware of the correct interval for screening mammogram and unable to accurately name two screening centres respectively. More than half (55.0\%) had poor understanding of what is considered to be screening mammogram and a third (33.6\%) did not know that Medisave can be used to pay for the screening mammogram.

This is alarming since BSS started in 2002 and the use of Medisave for screening practices was permitted in 2011. [12,13] Poor screening attendance may in part be due to some of these knowledge gaps. This reinforces the need for continual efforts to educate and spread awareness of the national screening program to healthcare staff who can then help to educate the population. [14]

\section{Domain 3 - Attitudes and perception of breast screening and cancer treatment}

The respondents' knowledge in this area was high except for the effect of breast cancer surgery on the ipsilateral arm. This misconception may be due to a bias higher prevalence of patient presenting to a tertiary hospital with lymphoedema. Hence, healthcare staff in a tertiary hospital are more likely to encounter such patients.

Feedback 
Majority of respondents' feedback that their preferred way of obtaining health information was via health talks. The authors suggest that for future talks, emphasis be placed in areas that were poor pre-talk (stage of breast cancer, BSS programme and breast cancer screening) with extra emphasis in areas that remained poor post-talk (risk factors, symptoms of breast cancer, traditional medicine, breast cancer screening). Future talks could also be tailored to the staff according to their area of work within the healthcare. For example, talks given to nurses, could have more prominence on information relating to breast cancer screening.

\section{Limitations}

We recognise that this study has a small sample size. In-person attendances suffers the constraint of venue capacity, hence limiting the number of attendees. To address this, more sessions and/or incorporating the talks into staff's protected learning time could be arranged. Future talks may also be conducted online, thus allowing for even greater attendants. This study was not designed to demonstrate that post-talk improvement in knowledge score would lead to an increase in screening practice

Nonetheless, this study was able to highlight the knowledge gaps in breast cancer screening and treatment in healthcare staff. Majority of these areas showed significant improvement simply after attending the talk. This is a simple and effective way to vastly improve health knowledge amongst healthcare staff. As healthcare personnel are ambassadors of the healthcare system, their knowledge would aid in providing accurate information to patients and public, enabling them to make wise healthcare choices.

\section{Conclusions}

This study has achieved its primary aim to identify certain knowledge gaps and perception towards breast cancer screening and treatment amongst healthcare staff. It also showed a significant post-talk improvement in knowledge scores, hence highlighting the effectiveness of such health talks. The authors endeavour to improve on future campaigns with targeted and relevant content.

\section{Abbreviations}

'CGH'- Changi General Hospital

'BSS'- BreastScreen Singapore

'BCAM'- Breast cancer awareness month

\section{Declarations}

\section{- Ethics approval and consent to participate}

The study protocol was reviewed and the need for approval was waived by the Singhealth Centralised Institutional Review Board (CIRB Ref no. 2019/ 2829) 


\section{- Consent for publication}

The authors provide consent for publication and need for consent was waived. The datasets used and analysed during the current study are available from the corresponding author on reasonable request.

- Competing interests - nil

- Funding - This study is funded by the Changi General Hospital Adhoc Grant 2020

\section{- Contribution}

Study concepts:

Study design:

Data acquisition:

Quality control of data and algorithms:

Data analysis and interpretation:

Statistical analysis:

Manuscript preparation:

Manuscript editing:

Manuscript review:
Author(s)

JX Hing, SM Tan

JX Hing, SM Tan

All

All

JX Hing, PT Tan, SM Tan

PT Tan, JX Hing

JX Hing, PT Tan, SM Tan

JX Hing, WP Lee, Chua YN, SM Tan

JX Hing, WP Lee, Chua YN, SM Tan

All authors have read and approved the manuscript.

- Name of corresponding author: Jun Xian Hing

- Corresponding author email: jun.xian@singhealth.com.sg

- Possible Conflict of Interest: No

- Number of Tables: 5 Number of Figures: 1

\section{- Acknowledgements}

The authors would like to thank staff at Changi General Hospital Breast Centre for supporting the annual breast cancer awareness activity.

\section{References}

1. Singapore Cancer Registry Annual Registry Report. 2015, National Registry of Diseases Office, Available at https://www.nrdo.gov.sg/docs/librariesprovider3/Publications-Cancer/cancer-registryannual-report-2015_web.pdf?sfvrsn=10.

2. Sim HL, Seah M, Tan SM. Breast cancer knowledge and screening practices: a survey of 1,000 Asian women. Singapore medical journal. 2009;50(2):132.

3. Loy EY, Molinar D, Chow KY, Fock C. National Breast Cancer Screening Programme, Singapore: evaluation of participation and performance indicators. J Med Screen. 2015;22(4):194-200. https://doi.org/10.1177/0969141315589644. 
4. Lim SK, Teo XL, Ng JL, Li FX, Tan SM. A Survey on Singaporean Women's Knowledge, Perception and Practices of Mammogram Screening. Annals of the Academy of MedicineSingapore. 2015;44(9):317-25.

5. Cancer screening. MOH clinical screening guidelines $1 / 2010$, available at https://www.moh.gov.sg/docs/librariesprovider4/guidelines/cpg_cancer-screening.pdf.

6. MediSave Central Provident Fund. Available at https://www.cpf.gov.sg/members/FAQ/schemes/healthcare/medisave/FAQDetails? category=healthcare\&group=MediSave\&ajfaqid=2189337\& folderid $=12909$.

7. Seah M, Tan SM. Am I breast cancer smart? Assessing breast cancer knowledge among health professionals. Singapore Med J. 2007 Feb;48(2):158-62. PMID: 17304397.

8. Wu TY, Chen SL. Breast Cancer Screening Practices and Related Health Beliefs among Taiwanese Nurses. Asia Pac J Oncol Nurs. 2017;4(2):104-11. doi:10.4103/2347-5625.204495.

9. Chong PN, Krishnan M, Hong CY, Swah TS. Knowledge and practice of breast cancer screening amongst public health nurses in Singapore. Singapore Med J. 2002 Oct;43(10):509-16. PMID: 12587705.

10. Heena H, Durrani S, Riaz M, et al. Knowledge, attitudes, and practices related to breast cancer screening among female health care professionals: a cross sectional study. BMC Women's Health. 2019;19:122. https://doi.org/10.1186/s12905-019-0819-x.

11. Koh H-L, Ng H-L, Teo H-H. A Survey on Knowledge, Attitudes and Usage of Complementary and Alternative Medicine in Singapore. Asia-Pacific Biotech News. 2004;08(23):1266-70. https://doi.org/10.1142/S0219030304002162.

12. Benefits. and remuneration, Available at https://polyclinic.singhealth.com.sg/careers/benefitsremuneration.

13. Wong XY, Chong KJ, van Til JA, Wee HL. A qualitative study on Singaporean women's views towards breast cancer screening and Single Nucleotide Polymorphisms (SNPs) gene testing to guide personalised screening strategies. BMC Cancer. 2017;17(1):776. Published 2017 Nov 21. doi:10.1186/s12885-017-3781-8.

14. Breast screening subsidies in Singapore. available at https://www.healthhub.sg/a-z/costs-andfinancing/30/breast-cancer-screening-subsidies.

\section{Figures}



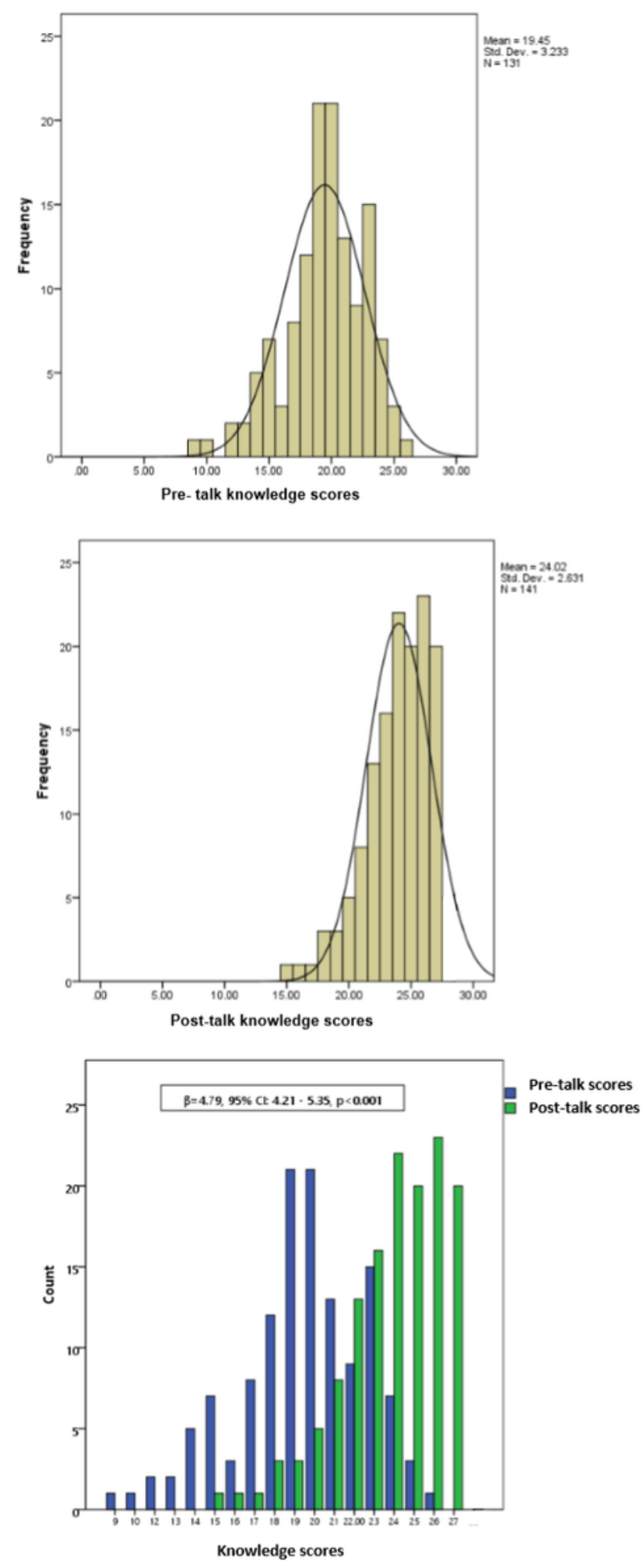

Figure 1

Analysis of knowledge scores pre and post talk.

\section{Supplementary Files}

This is a list of supplementary files associated with this preprint. Click to download. 
- BCAMSupplementarymaterials.docx 